\title{
Fatigue in Pregnancy
}

\section{The validity and reliability of the Farsi Multidimensional Assessment of Fatigue scale}

Forough Mortazavi ${ }^{1}$ and "Fateme Borzoee ${ }^{2}$

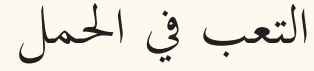

$$
\begin{aligned}
& \text { معداقية وموثوقية تقييم مقياس التعب الفارسي متعدد الأبعاد }
\end{aligned}
$$

$$
\text { فروغ مرتزافي و فاطمي بورزو }
$$

ABSTRACT: Objectives: Fatigue is a common discomfort experienced during pregnancy and may contribute to severe labour pain and postpartum depression. This study aimed to translate the Multidimensional Assessment of Fatigue (MAF) scale into Farsi and validate it in a sample of pregnant Irani women. Methods: This cross-sectional questionnaire study was conducted between January and June 2016 at eight healthcare centres in Sabzevar, Iran. The English version of the MAF scale was translated into Farsi and assessed for content validity. Participants completed the Farsi MAF scale and the Farsi World Health Organization-5 Well-being index (WHO-5). Construct validity was assessed through exploratory factor analysis (EFA). Cronbach's alpha coefficient and the intraclass correlation coefficient (ICC) were used to determine the internal consistency and stability of the Farsi MAF scale. Results: A total of 582 women met the inclusion criteria, of which 541 completed the MAF scale (response rate: 93\%). The EFA of the 15 items confirmed the previously proposed one-factor structure with a Cronbach's alpha coefficient of 0.957 for the Farsi MAF scale. Stability was confirmed by the ICC value (0.702) for the Global Fatigue Index (GFI) and the mean GFI was $20.33 \pm 12.71$. Concurrent validity was confirmed by a moderate negative correlation $(\mathrm{r}=-0.35$; $P<0.001$ ) between the scores of the Farsi MAF scale and the Farsi WHO-5. Women who received a high level of support from their husbands, who were satisfied with the quality of their marital relationship and with a well-being score of $>50$ reported a lower level of fatigue than the other groups $(P \leq 0.012)$. Conclusion: The Farsi MAF scale is a reliable and valid questionnaire to investigate fatigue in pregnant Irani women. Interventions to promote marital satisfaction and women's well-being are recommended.

Keywords: Fatigue; Parturition; Pregnancy; Psychometrics; Validation Studies; Reliability and Validity; Iran.

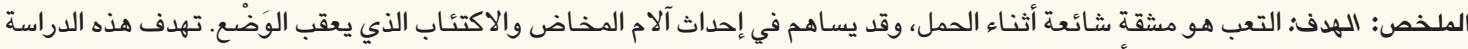

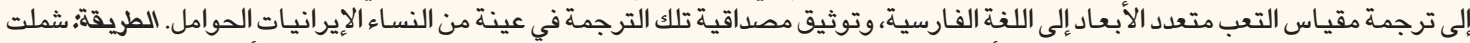

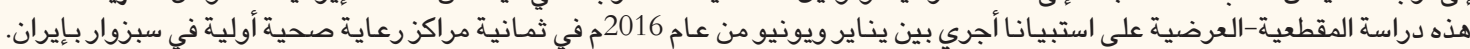

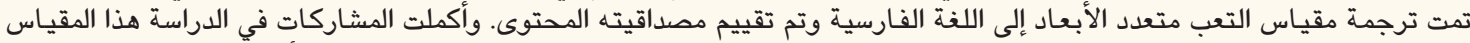

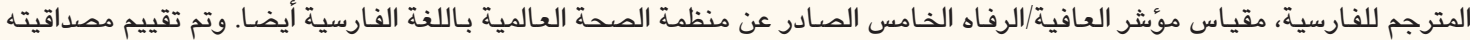

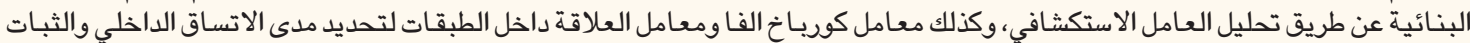

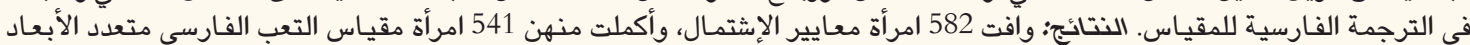

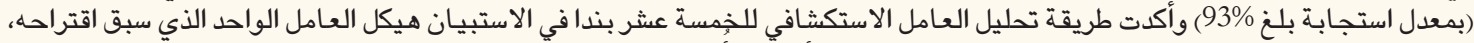

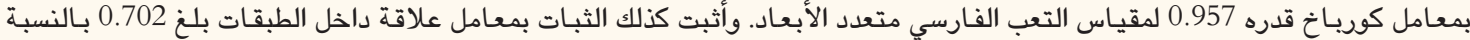

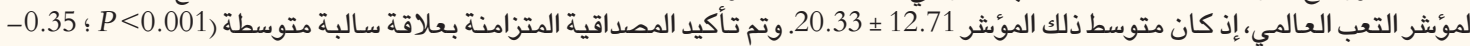

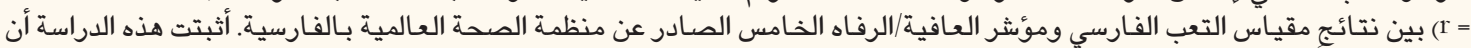

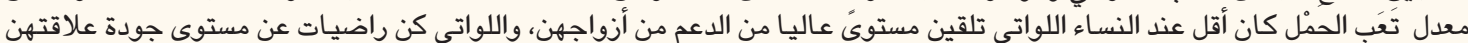

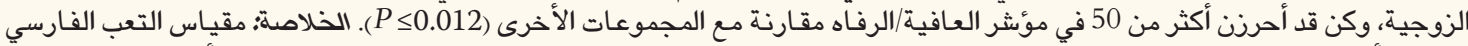

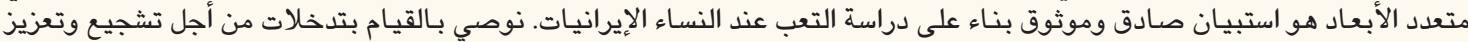
الرضا الزوجي ورفاه وعافية النساء.

الكلمات المفتاحية: التعب؛ الولادة؛ الحمل؛ قياس العمليات النفسية؛ دراسات التحقق من المصداقية؛ الموثوقية والمصداقية؛ إيران.

\section{AdVANCES IN KNOWLEDGE}

The Multidimensional Assessment of Fatigue (MAF) scale was translated into Farsi and validated under the Mapi Research Trust Guidelines for Cross-Cultural Adaptation and Linguistic Validation.

This study provides further evidence that the MAF scale may be an internationally reliable and valid instrument to measure fatigue in pregnant women.

\section{Application to Patient Care}

Measuring fatigue in pregnant women is the first step to designing interventions to reduce fatigue.

The MAF scale can be used to evaluate interventions affecting pregnant women's levels of fatigue. 
$\mathrm{P}$ REGNANCY IS ACCOMPANIED BY SEVERAL psychological, emotional and physical changes that may predispose the woman to fatigue, which can range from mild tiredness to severe exhaustion. ${ }^{1}$ Fatigue is defined as a feeling of consistently decreased energy; it is a symptom of many diseases, including anaemia, infection and hypothyroidism and is common during pregnancy. ${ }^{2,3}$ Most pregnant women feel some fatigue; however, some suffer from severe fatigue. A study of 197 pregnant Chinese women found that 95\% suffered from fatigue during pregnancy. ${ }^{4}$ Fatigue is positively correlated with low sexual activity and social interactions, as well as low maternal ability to provide infant care. ${ }^{2}$ Furthermore, severe fatigue can lower maternal quality of life and may increase labour pain. ${ }^{1,4}$

Measuring fatigue and its risk factors can help medical professionals screen pregnant women and design adequate interventions. ${ }^{5}$ Therefore, the development and validation of a scale to measure fatigue is necessary. As fatigue is a subjective experience, its measurement can be achieved through a self-reported scale. ${ }^{5}$ Belza originally designed the 16-item Multidimensional Assessment of Fatigue (MAF) scale, validated it in rheumatoid arthritis patients and proposed a single-factor structure for the scale. ${ }^{6,7} \mathrm{~A}$ recent systematic review on the scale indicated that the MAF scale has been translated into nine languages and used in 17 countries for 32 diseases. ${ }^{8}$ This scale was also validated in pregnancy and post-partum periods in a longitudinal study in Canada on two samples of pregnant English-speaking women. ${ }^{9}$

Currently there is no validated scale to assess fatigue in the prenatal period in Iran, which could lead to low knowledge of maternal fatigue and its risk factors and consequences. Therefore, this study aimed to translate, validate and investigate the factor structure of the MAF scale in pregnant Irani women. To the researchers' knowledge, no scale for measuring fatigue has been developed and no study has validated the MAF scale in Iran.

\section{Methods}

This cross-sectional study was conducted between January and June 2016 at eight healthcare centres in Sabzevar, Iran. Participants completed the Farsi MAF scale and World Health Organization-5 Well-being Index (WHO-5) in addition to sociodemographic and obstetrical information and psychosocial variables.

The sample size was estimated to be 500 based on Comrey and Lee's suggestion that researchers reach a sample of 500 or more for exploratory factor analysis (EFA). ${ }^{10}$ Receiver operating characteristics (ROC) curve power analysis was used to determine a cut-off point for the Global Fatigue Index (GFI) scores to predict a WHO-5 score of $<50$.
Cluster sampling was used whereby Sabzevar was divided into four different socioeconomic regions. In each region, two healthcare clinics were selected using a simple random method. Out of the 16 clinics affiliated with Sabzevar University of Medical Sciences, eight clinics were selected. These clinics provide free services including prenatal and post-partum care, vaccinations, family planning and infant growth monitoring. Midwives were instructed to include all women who attended the clinic throughout the day to receive prenatal care, had a positive pregnancy test or positive ultrasound scan and could read the questionnaire. Women who suffered from psychological disorders and/or received medical care for non-pregnancy conditions were excluded. In addition, women with chronic diseases and those with any sign or symptoms of gestational hypertension, preeclampsia, hyperemesis gravidarum, intrauterine fetal death or threatened abortion at the time of the study were excluded. Out of 674 women attending the clinics, 582 (86.3\%) met the inclusion criteria.

Midwives distributed the questionnaires and instructed the participants on how to complete them. Data collected included sociodemographic information, obstetrical information and psychosocial variables. Mothers' body mass indices (BMIs) and gestational age were calculated by midwives. After women completed the questionnaires, they were placed in envelopes and the midwives delivered the envelopes to the researchers.

Psychosocial variables were selected from previous studies that assessed fatigue., ${ }^{2,49} \mathrm{~A}$ four-point Likert scale was used to rate psychosocial items, with one representing 'not at all' and four indicating 'very good, always or severe'.

The Mapi Research Trust granted permission to translate and use the MAF scale before the start of the study. The translation and validation of the MAF scale was divided into two phases. In phase one, the MAF scale was translated into Farsi by two individuals using the Mapi Research Trust's Linguistic Validation Guideline. The two translated versions were compared and the first version of the Farsi MAF was made with few revisions. Back translation of the Farsi MAF into English was performed by another bilingual Irani-English language doctorate holder who was not familiar with the original scale. The main researcher then compared the original and translated versions of the MAF scale.

In phase two, the scale was validated. To determine content validity, ten experts in obstetrics or reproductive health were asked to appraise the wording and rate each item. Experts also judged the relevance of the scales' items to Irani culture. To determine the content validity ratio (CVR) of each item, Lawshe's method was used. ${ }^{11}$ Experts evaluated the necessity of the items on a threepoint rating scale, with one indicating 'not necessary'; 
two indicating that the item was 'useful, but not essential'; and three indicating that the item was 'essential. Experts also judged the clarity and simplicity of each item on a four-point Likert scale where one was 'not simple or clear' and four was 'very simple and clear.' ${ }^{\prime 2}$ Content validity indices (CVI) were calculated for the scale based on the experts' judgments.

To determine the face validity, 12 pregnant Farsi speakers who had completed a minimum of six years of schooling completed the Farsi MAF. These women were then interviewed individually and changes were made to the second version of the Farsi MAF scale. On average, the questionnaire was completed in 10 minutes. The scale was deemed easy for women who had completed their secondary education to read and understand; however, women with lower educational levels were confused about the phrasing in items 4-14. Therefore, the phrasing of these items was changed. All items were self-determining. After these changes, four pregnant women with middle level educations were asked to complete the Farsi MAF scale again and were then interviewed. Finally, the second Farsi MAF version was sent for language editing, where sentences were shortened and unnecessary prepositions were deleted in all items.

To assess the construct validity, 582 pregnant women who had registered to receive prenatal care in healthcare centres were included. No specific gestational age was considered for inclusion in the study. To determine the factorial structure of the Farsi MAF, an EFA was used and factors were extracted using principal component analysis. Items loading at $\geq 0.3$ and with eigenvalues $>1$ were retained in the model. ${ }^{13}$ To judge the concurrent validity of the scale, the correlation coefficient between the GFI scores and the WHO-5 scores were calculated. To determine the discriminant validity of the scale, a t-test or analysis of variance was used to compare the mean GFI in different demographic and psychosocial groups.

To determine the reliability of the Farsi MAF scale, 30 pregnant women completed the questionnaire. Cronbach's alpha coefficient values of $>0.7$ were considered acceptable. ${ }^{14}$ To assess stability over time, the MAF questionnaire was administered to the same women one week later. Test-retest reliability was examined using an intraclass correlation coefficient (ICC) for the GFI scores. ICCs of $0.61-0.80$ and $>0.80$ were considered good and excellent, respectively. ${ }^{15}$

The 16-item scale measures five dimensions of fatigue: degree of fatigue (item one), severity of fatigue (item two), level of distress (item three), degree of interference with daily life activities (items 4-14) and the frequency of feeling fatigued (items 15 and 16). Items 1-14 are scored on a 10-point Likert scale ranging from one 'not at all' to 10 'very much', while items 15 and 16 have multiple-choice responses.
According to Belza's instructions, the scores for item 15 were converted from $1-4$ to $2.5-10$; the scores for items 1-3 were summed and the means of items 4-14 and the new scores of item 15 were used to calculate the GFI. ${ }^{16}$ Item 16 was excluded from the analysis due to its different rating style. The GFI ranges from one 'no fatigue' to 50 'severe fatigue.' ${ }^{6}$ Convergent validity of the MAF scale was confirmed by the correlation of the MAF scale with the Fatigue Severity Scale $(r=0.74$; $P<0.001)$ and the Visual Analogue Scale for Fatigue ( $\mathrm{r}=0.42 ; P<0.001) .{ }^{17}$ A Cronbach's alpha of 0.93 confirmed the reliability of the scale. ${ }^{16}$ Factor analysis showed that the scale contains one factor. ${ }^{6,9,18}$ The concurrent validity of the MAF scale was also investigated by the correlation coefficients between the GFI scores and the WHO-5 scores.

The WHO-5 contains five items measuring the respondent's mental and subjective psychological wellbeing. ${ }^{19}$ Each item is scored on a six-point Likert scale where zero is 'never', one is 'some of the time', two is 'less than half of the time', three is 'more than half of the time', four is 'most of the time' and five is 'always'.

The total score of the WHO-5 are then converted into a scale ranging from $0-100$ where scores $\leq 50$ reflect a depressive state. The original version of the scale was translated into several languages, including Farsi by the Psychiatric Research Unit of the WHO Collaborating Centre for Mental Health and was validated using a sample of Irani pregnant women. ${ }^{19}$ The reliability of the WHO-5 was confirmed by a Cronbach's alpha coefficient of 0.85 . The correlation coefficient between the WHO-5 and the General Health Questionnaire-28 was -0.64 $(P<0.001)$ confirming concurrent validity. EFA revealed one factor and confirmatory factor analysis confirmed a single-factor structure. ${ }^{20}$

Data analyses were performed using Statistical Package for the Social Sciences (SPSS), Version 18 (IBM Corp., Armonk, New York, USA).

All participants signed an informed consent form before participating in the study. The questionnaires were anonymous and women were ensured of the confidentiality of their information. The study was approved by the Sabzevar University of Medical Sciences Ethics Committee (IR.MEDSAB.REC.1395.42).

\section{Results}

Of the 582 women who met the inclusion criteria, 541 completed the MAF scale (response rate: 93\%). Less than a quarter of the participants (20\%) had not experienced fatigue during the week before sampling. Mean age, BMI and haemoglobin level were $27.2 \pm 5.5$ years, $24.95 \pm 4.39 \mathrm{~kg} / \mathrm{m}^{2}$ and $12.52 \pm 0.85 \mathrm{~g} / \mathrm{dL}$, respectively. The mean gestational age and number of sleeping hours 
Table 1: Obstetric characteristics of pregnant Irani women $(\mathrm{N}=541)$

$\begin{array}{lcc}\text { Characteristic } & \text { Mean } \pm \text { SD } & P \text { value } \\ \text { Gestational age in weeks } & 23.24 \pm 10.00 & 0.786 \\ \text { Maternal age in years } & 27.20 \pm 5.50 & 0.859 \\ \begin{array}{l}\text { Interpregnancy interval } \\ \text { in years }\end{array} & 3.75 \pm 3.63 & 0.741 \\ \text { BMI in kg/m } & & \\ \text { Haemoglobin in g/dL } & 12.52 \pm 0.85 & 0.383 \\ \text { Sleep hours/24 hours in } & 9.00 \pm 2.08 & 0.174 \\ \text { hours } & & \\ \text { WHO-5 } & 63.78 \pm 20.46 & <0.001\end{array}$

$S D=$ standard deviation; $B M I=$ body mass index $;$ WHO-5 = World Health Organization-5 Well-being Index.

Table 2: Correlation between Global Fatigue Index scores and demographic characteristics of pregnant Irani women $(\mathrm{N}=541)$

\begin{tabular}{|c|c|c|c|}
\hline Characteristic & n (\%) & Mean GFI \pm SD & $P$ value \\
\hline \multicolumn{4}{|l|}{ Parity } \\
\hline None & $228(42.14)$ & $19.7 \pm 12.5$ & \multirow{2}{*}{0.366} \\
\hline One or more & $313(57.86)$ & $20.7 \pm 12.8$ & \\
\hline \multicolumn{4}{|c|}{ Number of years of education } \\
\hline$<12$ & $357(65.80)$ & $20.00 \pm 13.03$ & \multirow{2}{*}{0.414} \\
\hline$\geq 12$ & $184(34.20)$ & $21.01 \pm 12.13$ & \\
\hline \multicolumn{4}{|l|}{ Job } \\
\hline Housewife & $467(86.32)$ & $19.67 \pm 12.24$ & \multirow{2}{*}{0.005} \\
\hline Employed & $74(13.67)$ & $24.24 \pm 12.63$ & \\
\hline \multicolumn{4}{|c|}{ Household income } \\
\hline Insufficient & $70(12.93)$ & $20.67 \pm 14.52$ & \multirow{2}{*}{0.830} \\
\hline Sufficient & $471(87.06)$ & $20.31 \pm 12.45$ & \\
\hline
\end{tabular}

GFI = Global Fatigue Index; $S D=$ standard deviation.

in 24 hours were $23.24 \pm 10$ weeks and $9 \pm 2.08$ hours, respectively. Of the total, $42.2 \%$ were nulliparous and $23.8 \%$ reported a history of abortion [Table 1 ]. The mean GFI score was $20.33 \pm 12.70$ from a total of 50 , which indicates severe fatigue in the study's sample [Table 2]. No difference was found between fatigue scores in the three trimesters of pregnancy $(P=0.223)$.

All items in the Farsi MAF scale had a satisfactory CVR $(\geq 0.62)$. The scale's CVI was higher than 0.8 , which was an acceptable CVI cut-off value for the ten experts. ${ }^{21}$ Construct validity of the scale was investigated by EFA. Kaiser-Meyer-Olkin was 0.955 , indicating suitability of the data for EFA, and Bartlett's Test of Sphericity was $2,765(P<0.001)$, indicating adequate correlations between variables. For the EFA, missing data in items 4-14 were managed by replacing these scores with the mean score for the respective item. The EFA on the 15item Farsi MAF revealed one factor with eigenvalues $\geq 1$ [Table 3].
Table 3: The Farsi Multidimensional Assessment of Fatigue dimensions, item loading and means of each dimension of pregnant Irani women $(\mathrm{N}=541)$

\begin{tabular}{|c|c|c|c|c|}
\hline Dimension & $\begin{array}{l}\text { Item } \\
\text { no. }\end{array}$ & Question & $\begin{array}{l}\text { Factor } \\
\text { loading* }\end{array}$ & Mean \pm SD \\
\hline $\begin{array}{l}\text { Degree of } \\
\text { fatigue }\end{array}$ & 1 & $\begin{array}{l}\text { Within the last } \\
\text { week, how much } \\
\text { fatigue did you } \\
\text { experience? }\end{array}$ & 0.85 & $4.78 \pm 2.71$ \\
\hline $\begin{array}{l}\text { Severity of } \\
\text { fatigue }\end{array}$ & 2 & $\begin{array}{c}\text { Within the last } \\
\text { week, how strong } \\
\text { was your feeling of } \\
\text { fatigue? }\end{array}$ & 0.84 & $3.77 \pm 2.90$ \\
\hline $\begin{array}{l}\text { Distress } \\
\text { of feeling } \\
\text { fatigued }\end{array}$ & 3 & $\begin{array}{c}\text { Within the last } \\
\text { week, how much } \\
\text { has the feeling of } \\
\text { fatigue bothered } \\
\text { you? }\end{array}$ & 0.84 & $3.84 \pm 3.02$ \\
\hline \multirow{12}{*}{$\begin{array}{l}\text { Impact } \\
\text { of fatigue } \\
\text { on daily } \\
\text { activities }\end{array}$} & \multicolumn{4}{|c|}{$\begin{array}{l}\text { Within the last week, how much has fatigue decreased } \\
\text { your ability to do the activities listed below: }\end{array}$} \\
\hline & 4 & $\begin{array}{l}\text { Housework (e.g. } \\
\text { vacuuming, } \\
\text { washing dishes, } \\
\text { etc.) }\end{array}$ & 0.86 & $4.10 \pm 3.13$ \\
\hline & 5 & Cooking & 0.86 & $3.71 \pm 3.00$ \\
\hline & 6 & $\begin{array}{l}\text { Showering and } \\
\text { maintaining } \\
\text { personal hygiene }\end{array}$ & 0.82 & $3.28 \pm 2.78$ \\
\hline & 7 & $\begin{array}{l}\text { Dressing } \\
\text { and personal } \\
\text { grooming }\end{array}$ & 0.86 & $3.52 \pm 2.89$ \\
\hline & 8 & Working & 0.59 & $2.06 \pm 2.75$ \\
\hline & 9 & $\begin{array}{l}\text { Visiting friends } \\
\text { and relatives }\end{array}$ & 0.81 & $3.33 \pm 2.86$ \\
\hline & 10 & $\begin{array}{l}\text { Engaging in sexual } \\
\text { activity }\end{array}$ & 0.79 & $3.30 \pm 3.22$ \\
\hline & 11 & $\begin{array}{l}\text { Participating } \\
\text { in fun and } \\
\text { entertaining } \\
\text { activities }\end{array}$ & 0.85 & $3.63 \pm 3.00$ \\
\hline & 12 & $\begin{array}{l}\text { Shopping and } \\
\text { other activities } \\
\text { done outside of } \\
\text { the home (e.g. } \\
\text { going to the bank, } \\
\text { etc.) }\end{array}$ & 0.83 & $2.61 \pm 3.12$ \\
\hline & 13 & Walking & 0.83 & $3.43 \pm 2.94$ \\
\hline & 14 & $\begin{array}{l}\text { Exercising } \\
\text { (excluding } \\
\text { walking) }\end{array}$ & 0.70 & $2.89 \pm 3.01$ \\
\hline \multirow[t]{2}{*}{$\begin{array}{l}\text { Timing of } \\
\text { fatigue }\end{array}$} & 15 & $\begin{array}{l}\text { Within the last } \\
\text { week, how often } \\
\text { did you feel } \\
\text { fatigued? }\end{array}$ & 0.81 & $4.76 \pm 3.23$ \\
\hline & 16 & $\begin{array}{l}\text { Within the last } \\
\text { week, how has } \\
\text { your fatigue } \\
\text { changed? }\end{array}$ & - & $1.92 \pm 1.31$ \\
\hline GFI & - & - & - & $20.33 \pm 12.71$ \\
\hline $\begin{array}{l}\text { Variance } \\
\text { in } \%\end{array}$ & - & - & 65.82 & - \\
\hline Eigenvalue & - & - & 9.87 & - \\
\hline $\begin{array}{l}\text { Cronbach's } \\
\text { alpha } \\
\text { coefficient }\end{array}$ & - & - & 0.96 & - \\
\hline
\end{tabular}

"Kaiser-Meyer-Olkin $=0.96$ and Bartlett's Test of Sphericity $=2,765 ; P<0.001$. 
Table 4: Participants' psychosocial characteristics and the distribution of mean Global Fatigue Index scores $(\mathrm{N}=541)$

\begin{tabular}{|c|c|c|c|}
\hline Variables & n (\%) & $\begin{array}{l}\text { Mean GFI } \\
\quad \pm \text { SD }\end{array}$ & $P$ value \\
\hline \multicolumn{4}{|c|}{ Desirability of pregnancy } \\
\hline Yes & $390(72.08)$ & $19.00 \pm 12.51$ & \multirow{2}{*}{$<0.001$} \\
\hline No & $151(27.91)$ & $23.78 \pm 12.43$ & \\
\hline \multicolumn{4}{|l|}{ Request for CS } \\
\hline Yes & $168(31.05)$ & $19.83 \pm 12.56$ & \multirow{2}{*}{0.52} \\
\hline No & $373(68.95)$ & $20.62 \pm 12.57$ & \\
\hline \multicolumn{4}{|c|}{ Receiving support from husband } \\
\hline Very poor to acceptable & $92(17.00)$ & $24.00 \pm 13.24$ & \multirow{2}{*}{0.002} \\
\hline Good-to-very good & $449(82.00)$ & $19.45 \pm 12.43$ & \\
\hline \multicolumn{4}{|c|}{ Quality of relationship with husband } \\
\hline Dissatisfied & $39(7.20)$ & $25.24 \pm 13.74$ & \multirow[b]{2}{*}{0.012} \\
\hline $\begin{array}{l}\text { Moderately-to-very } \\
\text { satisfied }\end{array}$ & $502(92.79)$ & $19.90 \pm 12.53$ & \\
\hline \multicolumn{4}{|l|}{ Perceived health } \\
\hline Less than moderate & $28(5.18)$ & $32.67 \pm 11.34$ & \multirow{2}{*}{$<0.001$} \\
\hline Moderate-to-very good & $513(94.82)$ & $19.72 \pm 12.43$ & \\
\hline \multicolumn{4}{|c|}{ Women's description of pregnancy } \\
\hline Dissatisfied & $44(8.13)$ & $26.73 \pm 14.67$ & \multirow[b]{2}{*}{$<0.001$} \\
\hline $\begin{array}{l}\text { Moderately-to-very } \\
\text { satisfied }\end{array}$ & $497(91.87)$ & $19.78 \pm 12.34$ & \\
\hline \multicolumn{4}{|l|}{ Physical activity } \\
\hline$\leq 30$ minutes/week & $302(55.82)$ & $20.90 \pm 12.91$ & \multirow{2}{*}{0.336} \\
\hline$>30$ minutes/week & $239(44.18)$ & $19.78 \pm 12.34$ & \\
\hline \multicolumn{4}{|l|}{ Dyspareunia } \\
\hline None or mild & $383(70.79)$ & $19.43 \pm 12.20$ & \multirow{2}{*}{0.007} \\
\hline Moderate-to-severe & $158(29.21)$ & $22.60 \pm 13.34$ & \\
\hline \multicolumn{4}{|c|}{ History of dysmenorrhoea } \\
\hline None or mild & $355(65.62)$ & $19.34 \pm 12.33$ & \multirow{2}{*}{0.006} \\
\hline Moderate-to-severe & 186 (34.38) & $22.45 \pm 13.23$ & \\
\hline
\end{tabular}

GFI = Global Fatigue Index; $S D=$ standard deviation; $C S=$ Caesarean section .

To determine concurrent validity, the correlation coefficient between the GFI scores and the WHO-5 scores was calculated $(\mathrm{r}=-0.35 ; P<0.001)$, indicating a moderate negative correlation. Moreover, the Farsi MAF found a significant difference between employed women and housewives $(P=0.005)$ [Table 2]. In addition, women with unwanted pregnancies $(P<0.001)$, those unhappy with their pregnancies $(P<0.001)$, with poor self-perceived health $(P<0.001)$, women with a history of dysmenorrhoea $(P=0.006)$, those with dyspareunia $(P=0.007)$, those receiving low levels of emotional support from their husbands $(P=0.002)$ or with poorquality relationships with their husbands $(P=0.012)$ and women with low well-being status $(P<0.001)$ reported significantly higher levels of fatigue [Table 4].

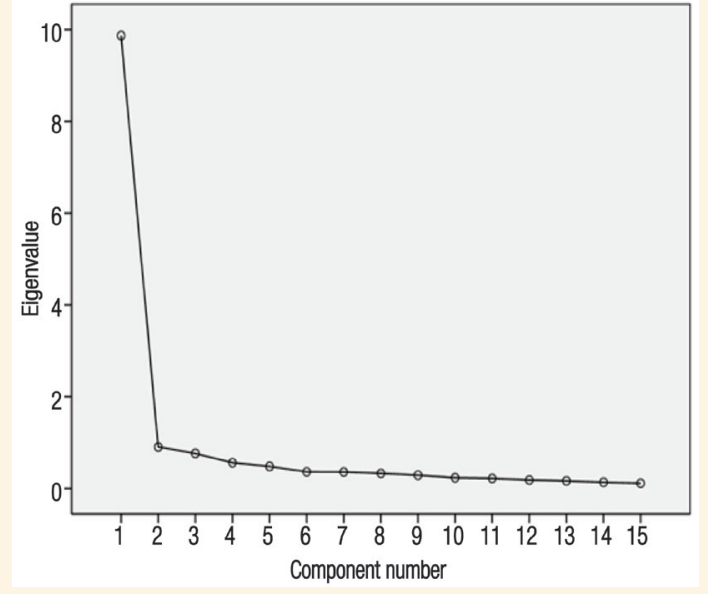

Figure 1: Scree plot for the exploratory factor analysis.

Cronbach's alpha coefficient for the 15-item Farsi MAF was 0.957. The ICC for the GFI scores was 0.702, confirming an acceptable stability of the scale. The scree plot supports a one-factor model [Figure 1]. Results of the ROC curve power analysis showed that a GFI cutoff of $>22.09$ had sensitivity and specificity of $70.1 \%$ and $62 \%$, respectively, in predicting a WHO-5 score $<50$ (area under the curve $=0.687 ; P<0.001$ ).

\section{Discussion}

The Farsi MAF scale, which was translated using the guidelines of the Mapi Research Trust, evaluates five dimensions of fatigue. Most participants answered all items, indicating that the scale is short, clear and easy to complete. The satisfactory CVR and CVI of all items indicates that the Farsi MAF scale is culturally suitable for measuring fatigue in pregnant Irani women.

The Farsi MAF scale had good internal consistency, which is in agreement with previous studies. ${ }^{22-25}$ Testretest analysis indicated that the GFI had acceptable stability. In a study of 51 patients with rheumatoid arthritis and 46 controls who completed the MAF scale three times at six-week intervals, the GFI showed excellent stability over time. ${ }^{17}$ In the current study, the EFA identified one factor. The scale developer and two previous studies proposed a one-factor model, whereas a study in the USA showed that the scale contained two factors. ${ }^{6,918,23}$

Concurrent validity was verified by the moderate negative correlation between the scores of the GFI and the WHO-5, indicating that women with lower levels of psychological well-being experienced higher fatigue. Fairbrother et al's study, conducted on pregnant women in Canada, found moderate correlations among the scores of the MAF scale, the Edinburgh Postnatal Depression Scale and the Beck Depression Inventory. ${ }^{9}$ Kuo et al's study on pregnant and post-partum women in Taiwan 
indicated a statistically significant relationship between fatigue in pregnancy and post-partum depression. ${ }^{24}$

Women who were glad about their pregnancies had a lower GFI than those who were not, which is in agreement with Cheng et al's study on 197 pregnant Chinese women with a gestational age $>24$ weeks. ${ }^{4}$ No relationship was detected between maternal age and fatigue, whereas in Wambach et al.'s study on 41 postpartum American women, maternal age was positively correlated with fatigue. ${ }^{26}$ In contrast, Hall et al.'s study on 650 pregnant Canadian women, found that younger women were more fatigued than older women. ${ }^{27}$

In the current study, a low percentage (3.5\%) of women reported sleep durations of less than six hours/ 24 hours. This finding may be the reason for the lack of a significant correlation between sleep duration and feeling fatigued. Tsai et al's study on 38 nulliparous Chinese women showed a significant inverse association between night sleep duration during pregnancy and morning and afternoon fatigue. ${ }^{28}$

The Farsi MAF scale could not discriminate between fatigue in nulliparous and multiparous women. This finding is inconsistent with Cheng et al's study in which the mean MAF score was higher in Chinese multiparous than nulliparous women. ${ }^{4}$ In the present study, there was no difference between fatigue scores in the three trimesters of pregnancy, whereas Cheng et al's longitudinal study showed that Chinese women in the third trimester of pregnancy endured a higher degree of fatigue than those in the first and second trimesters. ${ }^{4}$

Results indicated that a history of dysmenorrhoea or dyspareunia in the first encounter of sexual intercourse might play a role in severe fatigue in pregnancy. Brown et al. found that both of these characteristics may negatively affect women's attitudes toward their gender. ${ }^{29}$ Further studies are needed to investigate whether dysmenorrhoea and dyspareunia can induce unconscious negative feelings towards pregnancy, which may contribute to severe fatigue. In Mortazavi et al's study, Irani pregnant women with a history of moderate-to-severe dyspareunia in their first encounter of sexual intercourse were more likely to experience severe childbirth fears than their counterparts (odds ratio $=2.829$ ) ${ }^{30}$

In the current study, $20 \%$ of women reported no fatigue and their mean GFI score was $20.33 \pm 12.71$. In a previous study, the mean GFI scores were reported as $29.4 \pm 9.6$ and $25.4 \pm 9.6$ for samples one and two, respectively. ${ }^{9}$ In Chou et al.'s cross-sectional study on American women in their first trimester of pregnancy, $3.5 \%$ reported no fatigue, $43.4 \%$ reported occasional fatigue and $53.1 \%$ reported frequent fatigue in the previous month. ${ }^{31}$
A strength of the current study was its large sample size, which helped in the EFA; however, this study has some limitations. Convergent validity of the scale could not be examined due to lack of a previously validated Farsi fatigue questionnaire. In addition, although the test-retest interval should not be less than 15 days, the interval in this study was one week to minimise the normal progressive changes in fatigue between the two points in time.

\section{Conclusion}

The Farsi MAF scale is a reliable and valid questionnaire for measuring fatigue in pregnant Irani women. The scale can be used for screening fatigue in prenatal visits. The Farsi MAF scale can help healthcare providers identify pregnant women who are at risk of developing postpartum depression, premature birth or conditions associated with fatigue in pregnant women and design preventive measures accordingly. Interventions to improve marital satisfaction during pregnancy and increase husbands' awareness of the emotional needs during pregnancy should be designed. In addition, the importance of the first sexual encounter should be discussed in marital counselling programmes. Feeling fatigued may be a sign of a low state of well-being; thus, screening for depression in pregnant women is recommended.

\section{CONFLICT OF INTEREST}

The authors declare no conflicts of interest.

\section{FUNDING}

This study was conducted with the financial support of Sabzevar University of Medical Sciences (Project code: 94116).

\section{References}

1. Perry SE, Hockenberry MJ, Lowdermilk DL, Wilson D. Maternal Child Nursing Care. 5th ed. Missouri: Mosbey, 2014. P. 178.

2. Corwin EJ, Arbour M. Postpartum fatigue and evidence-based interventions. MCN Am J Matern Child Nurs 2007; 32:215-20. https://doi.org/10.1097/01.NMC.0000281959.71454.e5

3. Corton MM, Leveno K, Bloom S, Spong CY, Cunnigham JD. Williams Obstetrics. 24th ed. New York: McGraw Hill, 2010. P. 214.

4. Cheng CY, Chou YH, Wang P, Tsai JM, Liou SR. Survey of trend and factors in perinatal maternal fatigue. Nurs Health Sci 2015; 17:64-70. https://doi.org/10.1111/nhs.12149.

5. Lerdal A, Kottorp A, Gay CL, Lee KA. Development of a short version of the Lee Visual Analogue Fatigue Scale in a sample of women with HIV/AIDS: A Rasch analysis application. Qual Life Res 2013; 22:1467-722. https://doi.org/10.1007/s11136012-0279-3.

6. Belza B. Dimensions and correlates of fatigue in older adults with rheumatoid arthritis. PhD Thesis, 1991, University of California San Francisco, California, USA. 
7. Belza BL, Henke CJ, Yelin EH, Epstein WV, Gilliss CL. Correlates of fatigue in older adults with rheumatoid arthritis. Nurs Res 1993; 42:93-9. https://doi.org/10.1097/00006199-1993030 00-00006.

8. Belza B, Miyawaki CE, Liu M, Aree-Ue S, Fessel M, Minott KR, et al. A systematic review of studies using the Multidimensional Assessment of Fatigue scale. J Nurs Meas 2018; 26:36-75. https://doi.org/10.1891/1061-3749.26.1.36.

9. Fairbrother N, Hutton EK, Stoll K, Hall W, Kluka S. Psychometric evaluation of the Multidimensional Assessment of Fatigue scale for use with pregnant and postpartum women. Psychol Assess 2008; 20:150-8. https://doi.org/10.1037/1040-3590.20.2.150.

10. Comrey AL, Lee HB. A first course in factor analysis. hilsdale, NJ: Erlbaum, 1992. P. 32.

11. Lawshe $\mathrm{CH}$. A quantitative approach to content validity. Pers Psychol 1975; 28:563-75. https://doi.org/10.1111/j.1744-6570.19 75.tb01393.x.

12. Polit D, Beck C. Nursing Research: Principles and Methods. 46th ed. Philadelphia: Lippincott, 2004. P. 346.

13. Waltz CF, Strickland OL, Lenz ER. Measurement in Nursing and Health Research. 4th ed. New York: Springer Publishing Company, 2010. P. 602

14. Streiner DL. Starting at the beginning: An introduction to coefficient alpha and internal consistency. J Pers Assess 2003; 80:99-103. https://doi.org/10.1207/S15327752JPA8001_18.

15. Bartko JJ. Measures of agreement: A single procedure. Stat Med 1994; 13:737-45. https://doi.org/10.1002/sim.4780130534.

16. Winstead-Fry P. Psychometric assessment of four fatigue scales with a sample of rural cancer patients. J Nurs Meas 1998; 6:111-22. https://doi.org/10.1891/1061-3749.6.2.111.

17. Belza BL. Comparison of self-reported fatigue in rheumatoid arthritis and controls. J Rheumatol 1995; 22:639-43.

18. Lequerica A, Bushnik T, Wright J, Kolakowsky-Hayner SA, Hammond FM, Dijkers MP, et al. Psychometric properties of the Multidimensional Assessment of Fatigue scale in traumatic brain injury: An NIDRR Traumatic Brain Injury Model Systems study. J Head Trauma Rehabil 2012; 27:E28-35. https://doi.org/10. 1097/HTR.0b013e31826fe574.

19. Psykiatric Center North Zealand, Who-Five Well-being Index (WHO-5). 1999 version. From: www.who-5.org Accessed: Nov 2018.

20. Mortazavi F, Mousavi SA, Chaman R, Khosravi A. [Validation of the World Health Organization-5 Well-being Index; Assessment of maternal well-being and its associated factors]. Turk Psikiyatri Derg 2015; 26:48-55.
21. Polit DF, Beck CT, Owen SV. Is the CVI an acceptable indicator of content validity? Appraisal and recommendations. Res Nurs Health 2007; 30:459-67. https://doi.org/10.1002/nur.20199.

22. Bahouq H, Rostom S, Bahiri R, Hakkou J, Aissaoui N, HajjajHassouni N. Psychometric evaluation of the Arabic version of the Multidimensional Assessment of Fatigue scale (MAF) for use in patients with ankylosing spondylitis. Rheumatol Int 2012; 32:3969-76. https://doi.org/10.1007/s00296-011-2306-z.

23. Bormann J, Shively M, Smith TL, Gifford AL. Measurement of fatigue in HIV-positive adults: Reliability and validity of the Global Fatigue Index. J Assoc Nurses AIDS Care 2001; 12:75-83. https://doi.org/10.1016/s1055-3290(06)60146-5.

24. Kuo SY, Yang YL, Kuo PC, Tseng CM, Tzeng YL. Trajectories of depressive symptoms and fatigue among postpartum women. J Obstet Gynecol Neonatal Nurs 2012; 41:216-26. https://doi.org/10.1111/j.1552-6909.2011.01331.x.

25. Meek PM, Nail LM, Barsevick A, Schwartz AL, Stephen S, Whitmer K, et al. Psychometric testing of fatigue instruments for use with cancer patients. Nurs Res 2000; 49:181-90. https://doi.org/10.1097/00006199-200007000-00001.

26. Wambach KA. Maternal fatigue in breastfeeding primiparae during the first nine weeks postpartum. J Hum Lact 1998; 14:219-29. https://doi.org/10.1177/089033449801400311.

27. Hall WA, Hauck YL, Carty EM, Hutton EK, Fenwick J, Stoll K. Childbirth fear, anxiety, fatigue, and sleep deprivation in pregnant women. J Obstet Gynecol Neonatal Nurs 2009; 38:567-76. https://doi.org/10.1111/j.1552-6909.2009.01054.x.

28. Tsai SY, Lin JW, Kuo LT, Thomas KA. Daily sleep and fatigue characteristics in nulliparous women during the third trimester of pregnancy. Sleep 2012; 35:257-62. https://doi.org/10.5665/ sleep.1634.

29. Brown MA, Woods NF. Correlates of dysmenorrhea. A challenge to past stereotypes. JOGN Nurs 1984; 13:259-66. https://doi.org/10. 1111/j.1552-6909.1984.tb01137.x.

30. Mortazavi F, Agah J. Childbirth fear and associated factors in a sample of pregnant Iranian women. Oman Med J 2018; 33:497-505. https://doi.org/10.5001/omj.2018.91.

31. Chou FH, Kuo SH, Wang RH. A longitudinal study of nausea and vomiting, fatigue and perceived stress in, and social support for, pregnant women through the three trimesters. Kaohsiung J Med Sci 2008; 24:306-14. https://doi.org/10.1016/s1607-551x (08)70157-8 